\title{
Arquivos escolares e História da Educação: o que dizem os artigos do Portal de Periódicos da Capes/MEC (2002-2019)
}

\author{
School archives and History of Education: what is in the articles of the \\ Capes/MEC Journal Portal (2002-2019)
}

\author{
Joice Nunes de Souza \\ Mestranda em Educação - Bolsista CAPES \\ Universidade de Santa Cruz do Sul - PPGEdu -UNISC \\ Santa Cruz do Sul, RS - Brasil \\ joice15souza@gmail.com \\ Diego Orgel Dal Bosco Almeida \\ Doutor em História - PUC-RS \\ Em estágio pós-doutoral em Educação PNPD/CAPES na \\ Universidade de Santa Cruz do Sul - PPGEdu -UNISC \\ Santa Cruz do Sul, RS - Brasil. \\ diegoal@unisc.br \\ Éder da Silva Silveira \\ Doutor em História - Unisinos \\ Em estágio pós-doutoral em Educação - UFPR. \\ Professor pesquisador - Universidade de Santa Cruz do Sul - PPGEdu - UNISC \\ Santa Cruz do Sul, RS - Brasil \\ eders@unisc.br
}

Resumo: O presente artigo refere-se a um mapeamento preliminar de trabalhos de pesquisa que trataram dos arquivos escolares como objeto central de reflexão. Busca-se compreender o que dizem os trabalhos de pesquisa sobre organizar, sistematizar, preservar e inventariar fontes de arquivos escolares para a História da Educação. Para desenvolver a compreensão, utilizou-se da pesquisa bibliográfica inspirada por trabalhos sobre "estado do conhecimento" ou "estado da arte". Os trabalhos de pesquisa que tiveram arquivos escolares como objeto de reflexão central sugerem formas diversas de abordagem, organização, sistematização, preservação e construção de inventários que contribuem para a preservação da memória educativa e para a escrita da História da Educação no Brasil. Compreende-se, além disso, que trabalhos de pesquisa que fazem uso de arquivos escolares em seus percursos investigativos devem, ainda que não criem inventários completos, investir na descrição de potencialidades das fontes de pesquisa utilizadas.

Palavras-chave: Arquivos escolares. Inventários. Organização. Preservação. Sistematização.

Abstract: This article refers to a preliminary mapping of researches that dealt with school archives as a central object of reflection. It seeks to understand what the researches say about organizing, systematizing, preserving and inventorying sources of school archives for the History of Education. To develop understanding, bibliographic research inspired by works on "state of knowledge" or "state of art" was used. The researches that had school archives as the object of central reflection suggest different ways of approaching, organizing, systematizing, preserving and building inventories that contribute to the preservation of educational memory and to the writing of the History of Education in Brazil. It is also understood that researches that make use of school archives in their investigative pathways should, even if they do not create complete inventories, invest in describing the potential of the research sources used.

Key-words: School archives. Inventories. Organization. Preservation. Systematization.

Cite como

(ABNT NBR 6023:2018)

SOUZA, Joice Nunes de; ALMEIDA, Diego Orgel Dal Bosco; SILVEIRA, Éder da Silva. Arquivos escolares e História da Educação: o que dizem os artigos do Portal de Periódicos da Capes/MEC (2002-2019). Dialogia, São Paulo, n. 37, p. 1-13, e19356, jan./abr. 2021. Disponível em: https://doi.org/10.5585/dialogia.n37.19755.

American Psychological Association (APA)

Souza, J. N., Almeida, D. O. D. B., \& Silveira, É. da S. Arquivos escolares e História da Educação: o que dizem os artigos do Portal de Periódicos da Capes/MEC (2002-2019). Dialogia, São Paulo, 37, p. 1-13, e19356. https://doi.org/10.5585/dialogia.n37.19755. 
SOUZA, Joice Nunes de; ALMEIDA, Diego Orgel Dal Bosco; SILVEIRA, Éder da Silva. Arquivos escolares e História da Educação: o que dizem os artigos do Portal de Periódicos da Capes/MEC (2002-2019)

\section{Introdução}

As últimas décadas do século XX marcaram um período de transformação no campo da produção historiográfica. Além dos deslocamentos de abordagens metodológicas e domínios teóricos, modificou-se, essencialmente, o estatuto do documento, da fonte histórica. Com essa mudança, ganhou destaque o papel dos arquivos e suas associações com a memória e a escrita da história. A partir do incremento do conceito de "cultura escolar" (JULIA, 2001), passou-se a identificar e compreender o que havia na "caixa preta" das escolas, para além, portanto, dos regulamentos, das legislações e de estudos sobre ideias pedagógicas. A historiografia históricoeducacional passou a dar "maior atenção, nos últimos anos, à história do currículo, não já mais prescrito, mas vivido, à história da realidade e práticas escolares, do cotidiano, das culturas escolares, das reformas educativas e sua aplicação prática...” (VIÑAO FRAGO, 2004, p. 335). Além disso, também se tornou necessário pensar como se dá a preservação e a salvaguarda dos documentos escolares. Em um diagnóstico mais recente, Maria Helena Câmara Bastos (2019) considera que, mesmo com os notáveis avanços no campo da História da Educação, do ponto de vista teórico e metodológico, tem sido, cada vez mais, imprescindível a constituição de “inventários” destas fontes (BASTOS; BILHÃO; SILVEIRA, 2019, p. 254).

Neste texto pretendemos apresentar o mapeamento preliminar de trabalhos produzidos no Brasil, no campo da História da Educação, que elegeram os arquivos escolares como objeto central de reflexão. Nossa proposta surgiu de um movimento inicial de investigação que procura não só inventariar, mas localizar, identificar, sistematizar e compreender a situação de arquivos escolares na região dos vales, localizada no estado do Rio Grande do Sul/Brasil, especialmente no município de Santa Cruz do Sul. O projeto está atualmente em fase inicial junto ao Grupo de Pesquisa Currículo, Memórias e Narrativas em Educação (CNPq), vinculado ao Programa de Pós-graduação em Educação da Universidade de Santa Cruz do Sul (PPGEdu/UNISC) e já teve publicado alguns produtos de pesquisa (SOUZA; ALMEIDA; SILVEIRA, 2020).

O que apresentamos nas páginas seguintes é resultado de um estudo de natureza bibliográfica que teve como objetivo central compreender o que dizem os trabalhos de pesquisa sobre organizar, sistematizar, preservar e inventariar fontes de arquivos escolares para a História da Educação. Inspiramo-nos em estudos sobre "estado do conhecimento" ou "estado da arte", tendo em vista que são pesquisas de "caráter inventariante" acerca do tema que se busca investigar, utilizando categorias que se caracterizam enquanto tais na medida em que são vistas tanto no modo como são mobilizadas em cada trabalho quanto no conjunto deles (FERREIRA, 2002, p. 258). Com as discussões que foram desenvolvidas em nosso grupo de pesquisa, entendemos, como 
esclarecem Morosini e Fernandes (2014), que esse tipo de estudo possibilita uma visão ampliada da atualidade dos movimentos da pesquisa. O texto está dividido em duas partes: na primeira, relatamos as estratégias e os pressupostos que construímos para realizar o levantamento no Portal de Periódicos Capes/MEC, ressaltando que os termos-chave (descritores) escolhidos provém das leituras coletivas realizadas em nosso Grupo de Pesquisa, além de se configurarem como estratégias para efetivamente cercar o objeto de investigação. $\mathrm{Na}$ segunda parte, buscamos identificar os objetivos e as principais considerações dos trabalhos de pesquisa que se detiveram aos arquivos escolares como objetos centrais de suas reflexões a fim de traçar os contornos das possibilidades de nossa incursão pelos arquivos escolares do município de Santa Cruz do Sul. Neste percurso, concluímos a necessidade de que não só as pesquisas sobre arquivos escolares, mas também as que se utilizam dessas fontes em seus temas específicos, atentem para a descrição da situação das fontes pesquisadas e a caracterização de suas potencialidades para novas pesquisas.

Os “Arquivos escolares" entre aspas: estratégias e pressupostos para o levantamento realizado no Portal de Periódicos Capes/MEC

Ao realizarmos nosso movimento inicial de pesquisa, optamos por palavras-chave que pudessem corresponder ao maior número de trabalhos sobre o tema que investigamos, qual seja, os arquivos escolares. Daí que "arquivos escolares" foi um de nossos descritores, combinados a outros termos. Empregando aspas em cada um deles e o operador booleano AND, o gerador combina os termos exatos do levantamento, recuperando trabalhos de pesquisa cujos títulos ou temáticas contenham as palavras-chave da busca. Assim, o levantamento se deu tanto por ações estratégicas (procurar por lacunas no conhecimento na medida em que verificamos o que mais interessou às pesquisas já realizadas), quanto pelo interesse em um mapeamento de percursos que pudesse fornecer experiências consideradas úteis no trabalho desenvolvido com ou a partir dos arquivos escolares. Os resultados obtidos aparecem esquematizados no quadro-síntese que segue na sequência. 
Quadro 1 -Total geral de artigos sobre arquivos escolares

\begin{tabular}{|c|c|c|}
\hline Repositório & Descritores & Total de resultados \\
\hline \multirow{4}{*}{$\begin{array}{c}\text { Portal de } \\
\text { Periódicos Capes }\end{array}$} & $\begin{array}{c}\text { "Arquivos Escolares" AND "História da } \\
\text { Educação" }\end{array}$ & 13 \\
\cline { 2 - 3 } & "Arquivo Escolar" AND "História da Educação" & 1 \\
\cline { 2 - 3 } & "Arquivos Escolares" AND "Rio Grande do Sul" & 1 \\
\cline { 2 - 3 } & "Arquivo Escolar" AND "Memória" & 1 \\
\cline { 2 - 3 } & "Arquivos Escolares" AND "Cultura escolar" & 1 \\
\hline
\end{tabular}

Fonte: Elaborado pelos autores e pela autora a partir do Portal de periódicos da Capes/MEC, fevereiro, 2021.

Na sequência, além de mostrar os resultados obtidos, procuramos justificar as escolhas que fizemos dos descritores relacionando-os, em parte, com as leituras realizadas no decorrer dos encontros de nosso Grupo de Pesquisa no período 2019-2020. Entendemos que essa justificativa e esse detalhamento são importantes porque vão além apenas do procedimento técnico de busca e informam qualitativamente nossas opções e percursos, auxiliando tanto quem nos lê quanto a nós mesmos a compreender mais e melhor como, afinal, fomos gradualmente construindo nossa proposição de pesquisa.

Dos resultados obtidos no levantamento realizado no Portal de Periódicos Capes/MEC, foi possível dividir em dois conjuntos os trabalhos encontrados: o primeiro conjunto, de maior número, são trabalhos de pesquisa que tratam diretamente da organização, sistematização, conservação ou constituição de inventários de fontes provenientes de arquivos escolares; o segundo conjunto, numericamente menor, são trabalhos sobre temas diversos em que os arquivos escolares são imprescindíveis, mas seus autores e autoras não fornecem, por exemplo, elementos para pensar inventários de fontes ou mesmo sua sistematização, limitando-se apenas a referenciálas a fim de cumprir os objetivos específicos de suas investigações. Os trabalhos que nos interessavam, desde o início, referem-se ao primeiro grupo: os que valorizaram os arquivos escolares enquanto tema principal ou valorizaram esse tema em suas proposições específicas. $\mathrm{Na}$ sequência, um quadro contendo os resultados obtidos no levantamento, em ordem cronológica e os links de acesso correspondentes dos textos recuperados. 
SOUZA, Joice Nunes de; ALMEIDA, Diego Orgel Dal Bosco; SILVEIRA, Éder da Silva. Arquivos escolares e História da Educação: o que dizem os artigos do Portal de Periódicos da Capes/MEC

Quadro 2 - Sistematização dos artigos consultados

\begin{tabular}{|c|c|c|c|c|}
\hline \multicolumn{5}{|c|}{ “Arquivos Escolares” AND “História da Educação” } \\
\hline ANO & AUTOR/A & TÍTULO & PERIÓDICO & LINK \\
\hline 2002 & $\begin{array}{l}\text { Flávia Obino Corrêa } \\
\text { Werle }\end{array}$ & $\begin{array}{c}\text { Documentos escolares: impactos das novas } \\
\text { tecnologias }\end{array}$ & $\begin{array}{l}\text { Revista História da } \\
\text { Educação } \\
\end{array}$ & Link \\
\hline 2005 & $\begin{array}{l}\text { Nailda Marinho da } \\
\text { Costa Bonato }\end{array}$ & $\begin{array}{l}\text { Os arquivos escolares como fonte para a história da } \\
\text { educação }\end{array}$ & $\begin{array}{l}\text { Revista Brasileira de } \\
\text { História da Educação }\end{array}$ & Link \\
\hline 2005 & $\begin{array}{l}\text { Wagner Rodrigues } \\
\text { Valente }\end{array}$ & $\begin{array}{c}\text { Arquivos escolares virtuais: considerações sobre uma } \\
\text { prática de pesquisa }\end{array}$ & $\begin{array}{l}\text { Revista Brasileira de } \\
\text { História da Educação }\end{array}$ & Link \\
\hline 2005 & $\begin{array}{l}\text { Elizabeth Madureira } \\
\text { Siqueira }\end{array}$ & $\begin{array}{l}\text { Reconstituindo arquivos escolares: a experiência do } \\
\text { GEM/MT }\end{array}$ & $\begin{array}{l}\text { Revista Brasileira de } \\
\text { História da Educação }\end{array}$ & Link \\
\hline 2005 & Jacy Machado Barletta & $\begin{array}{c}\text { Arquivos ou museus: qual o lugar dos acervos } \\
\text { escolares? }\end{array}$ & $\begin{array}{l}\text { Revista Brasileira de } \\
\text { História da Educação }\end{array}$ & Link \\
\hline 2005 & Iomar Barbosa Zaia & $\begin{array}{l}\text { O lugar do arquivo permanente dentro de um centro } \\
\text { de memória escolar }\end{array}$ & $\begin{array}{l}\text { Revista Brasileira de } \\
\text { História da Educação }\end{array}$ & Link \\
\hline 2005 & Maria João Mogarro & $\begin{array}{c}\text { Arquivos e educação: a construção da memória } \\
\text { educativa }\end{array}$ & $\begin{array}{l}\text { Revista Brasileira de } \\
\text { História da Educação }\end{array}$ & Link \\
\hline 2010 & $\begin{array}{l}\text { Décio Gatti Júnior e } \\
\text { Eurize Caldas Pessanha }\end{array}$ & $\begin{array}{c}\text { Currículos, práticas e cotidiano escolar: a importância } \\
\text { dos arquivos escolares para a produção de } \\
\text { conhecimento em história da educação }\end{array}$ & $\begin{array}{l}\text { Revista História da } \\
\text { Educação }\end{array}$ & Link \\
\hline 2011 & Maria Cristina Menezes & $\begin{array}{l}\text { Descrever os documentos - construir o inventário - } \\
\text { preservar a cultura material escolar }\end{array}$ & $\begin{array}{l}\text { Revista Brasileira de } \\
\text { História da Educação }\end{array}$ & Link \\
\hline 2011 & $\begin{array}{l}\text { Carmen Sylvia Vidigal } \\
\text { Moraes; Daniel Righi; } \\
\text { Luciana Santos; Tatiana } \\
\text { Calsavara }\end{array}$ & $\begin{array}{l}\text { Inventário de fontes das escolas dirigidas pelo } \\
\text { educador anarquista João Penteado (1912-1961): } \\
\text { dimensão pedagógica e contribuição para a história da } \\
\text { relação trabalho e educação no Brasil }\end{array}$ & $\begin{array}{l}\text { Revista Brasileira de } \\
\text { História da Educação }\end{array}$ & Link \\
\hline 2011 & $\begin{array}{l}\text { Laerthe de Moraes } \\
\text { Abreu Jr. e Paula David } \\
\text { Guimarães }\end{array}$ & $\begin{array}{c}\text { A Cultura Material Escolar como Fonte de Pesquisa } \\
\text { das Práticas Escolares em São João del-Rei, MG (1938 } \\
-1944)\end{array}$ & $\begin{array}{l}\text { Educação: teoria e } \\
\text { prática }\end{array}$ & Link \\
\hline 2013 & $\begin{array}{l}\text { Ane Caroline Pereira } \\
\text { Cruz }\end{array}$ & $\begin{array}{c}\text { Educação pública e arquivos: uma abordagem sobre a } \\
\text { formação de professores das séries iniciais em } \\
\text { Dourados (1970-2000) }\end{array}$ & $\begin{array}{l}\text { Horizontes - Revista de } \\
\text { Educação }\end{array}$ & Link \\
\hline 2014 & $\begin{array}{l}\text { Aline Nascimento } \\
\text { Cavalcante e Alessandra } \\
\text { Cristina Furtado }\end{array}$ & $\begin{array}{l}\text { Organização e digitalização de documentos sobre a } \\
\text { formação e profissionalização de professores das } \\
\text { escolas rurais de Dourados e região (1988-1996) }\end{array}$ & $\begin{array}{l}\text { Revista Interfaces da } \\
\text { Educação }\end{array}$ & Link \\
\hline \multicolumn{5}{|c|}{ “Arquivo Escolar” AND “História da Educação” } \\
\hline 2019 & $\begin{array}{l}\text { Marcelo Cigales e } \\
\text { Eduardo Arriada }\end{array}$ & $\begin{array}{l}\text { A sociologia educacional católica no sul do Brasil } \\
\text { (1940-1970): um estudo a partir do corpo docente }\end{array}$ & $\begin{array}{l}\text { Acta Scientiarum. } \\
\text { Education }\end{array}$ & Link \\
\hline \multicolumn{5}{|c|}{ “Arquivos Escolares" AND "Rio Grande do Sul” } \\
\hline 2011 & $\begin{array}{l}\text { Flávia Obino Corrêa } \\
\text { Werle }\end{array}$ & $\begin{array}{l}\text { O rádio e a educação rural no Rio Grande do Sul } \\
\qquad(1940-1960)\end{array}$ & $\begin{array}{l}\text { Revista História da } \\
\text { Educação }\end{array}$ & Link \\
\hline \multicolumn{5}{|c|}{ “Arquivo Escolar" AND "Memória” } \\
\hline 2014 & André Vinícius Hidalgo & $\begin{array}{c}\text { Educação Física escolar no Curso de Formação em } \\
\text { Nível Médio para professores Guarani e Kaiowá: } \\
\text { memória da turma } 2001\end{array}$ & $\begin{array}{l}\text { Horizontes - Revista de } \\
\text { Educação }\end{array}$ & Link \\
\hline \multicolumn{5}{|c|}{ “Arquivos Escolares" AND “Cultura escolar” } \\
\hline 2018 & $\begin{array}{l}\text { Yohana T. Hoffmann e } \\
\text { David A. Costa }\end{array}$ & $\begin{array}{l}\text { História da educação matemática: conservação da } \\
\text { cultura escolar }\end{array}$ & $\begin{array}{l}\text { Revista latinoamericana } \\
\text { de investigación en } \\
\text { matemática educativa }\end{array}$ & Link \\
\hline
\end{tabular}

Fonte: Elaborado pelos autores e pela autora a partir do Portal de periódicos da Capes/MEC, fevereiro, 2021. 
Do total de 17 trabalhos encontrados, 11 deles se detiveram a problematizar aspectos centrais relacionados aos arquivos escolares sobre: situação das fontes, condições dos acervos, constituição de bases de dados ou inventários e catalogação de fontes de pesquisa (BONATO, 2005; GATTI JR e PESSANHA, 2010; VALENTE, 2005; SIQUEIRA, 2005; MENEZES, 2011; MORAES et al.; 2011; BARLETTA, 2005; ZAIA, 2005; MOGARRO, 2005; CRUZ, 2013; HOFMANN e COSTA, 2018). Desses, 10 foram encontrados no sistema a partir da associação dos seguintes descritores: “arquivo escolar"/“arquivos escolares” AND "História da Educação". Apenas um foi encontrado com os descritores “arquivos escolares" AND “Cultura escolar”. Outros trabalhos, cujo objetivo principal não se deteve a problematizar os arquivos escolares, mas sim outros temas, embora tenham se utilizado de fontes oriundas desses arquivos, totalizaram um conjunto de 6 trabalhos (WERLE, 2002; ABREU JR. e GUIMARÃES, 2011; CAVALCANTE e FURTADO, 2014; CIGALES e ARRIADA, 2019; WERLE, 2011; HIDALGO, 2014). Desses 6, 2 deles foram obtidos com a utilização dos descritores "arquivos escolares” AND “memória” e “arquivos escolares” AND "Rio Grande do Sul”. O restante também apareceu a partir da utilização de “arquivo escolar”/“arquivos escolares” AND “História da Educação”. Focalizamos, neste texto, como já dissemos, em trabalhos que se detiveram aos arquivos escolares mais diretamente ou valorizaram a descrição e o detalhamento de potencialidades de fontes oriundas desses arquivos no desenvolvimento de suas investigações.

Ao escolher, por exemplo, a associação “arquivos escolares AND História da Educação" estávamos cientes das transformações do campo de estudo histórico-educacional, sobretudo nas últimas três décadas, com o delineamento do domínio da história das instituições escolares, que ganhou concretude nos anos 1990 e que vem se consolidando ao longo das duas primeiras décadas dos anos 2000/2010 (NÓVOA, 2011; VIÑAO FRAGO, 2004; NOSELLA; BUFFA, 2006).

Ao optarmos pela associação entre “Arquivos Escolares” AND “Cultura escolar”, consideramos as modificações do campo de estudos da História da Educação a partir dos anos 1990 e o deslocamento do interesse das pesquisas que vinham se delineando entre os anos 1970 e 1980. O conceito de "cultura escolar", que se constitui na relação entre "normas" e "práticas" do cotidiano da escola e da sociedade - e que "podem variar segundo as épocas (finalidades religiosas, sociopolíticas ou simplesmente de socialização)" -, provocou uma renovação dos objetos e temas. Através desse conceito “os arquivos escolares ganharam maior atenção nas pesquisas em História da educação. Passou-se a considerar não apenas aspectos normativos e legislativos "que definem conhecimentos a ensinar e condutas a inculcar", mas também "um conjunto de práticas que 
permitem a transmissão desses conhecimentos e a incorporação desses comportamentos" (JULIA, 2001, p. 10). Acerca da relação entre arquivos escolares e cultura escolar, podemos dizer que o:

[...] conceito de "cultura escolar" promoveu mudanças de perspectivas muito significativas nos estudos de História da Educação, sobretudo a de que os diferentes contextos históricos e as relações estabelecidas entre professores/as, estudantes e demais envolvidos/as no processo educativo escolar influenciaram as formas pelas quais as normas foram interpretadas e vividas no cotidiano. Os arquivos escolares, neste sentido, emergem como temática recorrente no campo da História da Educação, tendo em vista a multiplicidade de abordagens e perspectivas de compreensão que podem ser consideradas . (SOUZA; ALMEIDA; SILVEIRA, 2020, p. 431-432).

Outra dimensão que orientou a escolha dos descritores utilizados no levantamento está relacionada à categoria patrimônio documental. Ao lidarmos com arquivos históricos, conforme o que diz Bellotto (2000, p. 152), “estamos no domínio do patrimônio documental, caudatário do patrimônio cultural”. Essa dimensão compreende que os registros dos comportamentos e experiências produzidos ao longo da história acabam por constituir o patrimônio cultural de uma sociedade:

\begin{abstract}
Constituem patrimônio documental somente aqueles documentos que: - já cumpriram sua função imediata, ligada à razão pela qual foram gerados; - que já não tramitam; - que já passaram pelo arquivo corrente; - que, já submetidos às tabelas de temporalidade, foram avaliados como de valor permanente, pela densidade de seu valor informativo testemunhal tanto para a história institucional da entidade que $O$ produziu/recebeu/acumulou, como para a sociedade, em cujo contexto viveu e atuou esta instituição. Esses conjuntos documentais, portanto, reunidos nos arquivos permanentes também chamados históricos, vêm a constituir o patrimônio documental institucional, municipal, provincial/estadual ou nacional. (BELLOTTO, 2000, p. 154).
\end{abstract}

O patrimônio documental dos arquivos escolares faz referência ao conteúdo desses arquivos permanentes. Eles são elementos importantes na constituição do patrimônio cultural, uma vez que seus acervos documentais são bens culturais e, ao mesmo tempo, suportes que registram práticas sociais e memórias individuais, coletivas e institucionais. Assim, ao optarmos pelos termoschave “Arquivo Escolar” AND “Memória”, o fizemos estando a par das discussões sobre as transformações do estatuto do documento e da fonte histórica e da premissa de que os arquivos escolares podem ser compreendidos como patrimônios documentais relacionados à memória social. Propriamente na dimensão da memória, entendemos que "o arquivo escolar garante, em cada instituição, a unidade, a coerência e a consistência que as memórias individuais sobre a escola ou os objetos isolados por ela produzidos e utilizados não podem conferir" (MOGARRO, 2005, p. 86). Para quem pesquisa no campo da História da Educação, a memória torna-se, portanto, um dos principais "[...] indícios, documento de que se serve o historiador [e a historiadora] para 
produzir leituras do passado, do vivido, do sentido [...] pelos indivíduos e daquilo que se lembram e esquecem a um só tempo" (STEPHANOU; BASTOS, 2011, p. 418).

Procuramos demonstrar, nesta primeira parte do texto, além dos resultados obtidos, também parte do percurso que nos levou a escolher os termos-chave que foram utilizados em nosso levantamento. Entendemos que não só como simples procedimento técnico, esse movimento inicial, de toda e qualquer pesquisa, precisa aparecer detalhadamente justificado. No nosso caso, os termos funcionaram estrategicamente no intuito de cercar o tema, sendo escolhidos a partir das leituras e discussões que realizamos no percurso de nossa pesquisa acerca de estatutos teóricos e metodológicos na História da Educação.

“Arquivos escolares" entre outras aspas: o que dizem os trabalhos de pesquisa sobre organizar, sistematizar, preservar e inventariar fontes para a História da Educação?

Podemos caracterizar as pesquisas que se dedicaram a problematizar a organização e sistematização de fontes provenientes de acervos de arquivos escolares de maneira bastante ampla. Identificamos, ao menos, três conjuntos de trabalhos. $\mathbf{O}$ primeiro apareceu circunscrito enquanto "diagnóstico", “condição e localização", "lugares" e "potencialidades". São trabalhos de pesquisa que buscaram fazer "diagnósticos" da situação de fontes de arquivos escolares, caracterizar suas "condições e localização", refletir sobre os "lugares" dos objetos nesses arquivos e detalhar sobre suas "potencialidades". O segundo conjunto foi o de trabalhos que se detiveram à construção de "base de dados", "sistematização de documentos" e à construção/constituição de "inventários". O terceiro conjunto refere-se a um trabalho de pesquisa em fase mais adiantada que, além de relatar a experiência de tratamento de documentos de arquivos de escolas públicas, propõe organizar um centro de memória escolar capaz não só de contemplar documentos administrativos e legais, mas também objetos e outros tipos documentais, de maneira interdisciplinar. A seguir, um quadro contendo os artigos que apresentam arquivos escolares como objeto central de reflexão, sistematizados por ordem cronológica de publicação. 
Quadro 3 - Trabalhos que apresentam arquivos escolares como objeto central de reflexão

\begin{tabular}{|c|c|c|c|c|}
\hline ANO & AUTOR/A & TÍTULO & PERIÓDICO & LINK \\
\hline 2005 & $\begin{array}{l}\text { Nailda Marinho da } \\
\text { Costa Bonato }\end{array}$ & $\begin{array}{l}\text { Os arquivos escolares como fonte para a } \\
\text { história da educação. }\end{array}$ & $\begin{array}{l}\text { Revista Brasileira de } \\
\text { História da Educação }\end{array}$ & $\underline{\text { Link }}$ \\
\hline 2005 & $\begin{array}{l}\text { Wagner Rodrigues } \\
\text { Valente }\end{array}$ & $\begin{array}{c}\text { Arquivos escolares digitais: considerações } \\
\text { sobre uma prática de pesquisa }\end{array}$ & $\begin{array}{l}\text { Revista Brasileira de } \\
\text { História da Educação }\end{array}$ & $\underline{\text { Link }}$ \\
\hline 2005 & $\begin{array}{c}\text { Elizabeth Madureira } \\
\text { Siqueira }\end{array}$ & $\begin{array}{l}\text { Reconstituindo arquivos escolares: a } \\
\text { experiência do GEM/MT. }\end{array}$ & $\begin{array}{l}\text { Revista Brasileira de } \\
\text { História da Educação }\end{array}$ & $\underline{\text { Link }}$ \\
\hline 2005 & $\begin{array}{c}\text { Jacy Machado } \\
\text { Barletta }\end{array}$ & $\begin{array}{c}\text { Arquivos ou museus: qual o lugar dos acervos } \\
\text { escolares? }\end{array}$ & $\begin{array}{l}\text { Revista Brasileira de } \\
\text { História da Educação }\end{array}$ & $\underline{\text { Link }}$ \\
\hline 2005 & Iomar Barbosa Zaia & $\begin{array}{l}\text { O lugar do arquivo permanente dentro de um } \\
\text { centro de memória escolar. }\end{array}$ & $\begin{array}{l}\text { Revista Brasileira de } \\
\text { História da Educação }\end{array}$ & $\underline{\text { Link }}$ \\
\hline 2010 & $\begin{array}{l}\text { Décio Gatti Júnior e } \\
\text { Eurize Caldas } \\
\text { Pessanha }\end{array}$ & $\begin{array}{c}\text { Currículos, práticas e cotidiano escolar: a } \\
\text { importância dos arquivos escolares para a } \\
\text { produção de conhecimento em história da } \\
\text { educação. }\end{array}$ & $\begin{array}{l}\text { Revista História da } \\
\text { Educação }\end{array}$ & $\underline{\text { Link }}$ \\
\hline 2010 & Maria João Mogarro & $\begin{array}{l}\text { Arquivos e educação: a construção da } \\
\text { memória educativa. }\end{array}$ & $\begin{array}{l}\text { Revista Brasileira de } \\
\text { História da Educação }\end{array}$ & $\underline{\text { Link }}$ \\
\hline 2011 & $\begin{array}{l}\text { Maria Cristina } \\
\text { Menezes }\end{array}$ & $\begin{array}{c}\text { Descrever os documentos - construir o } \\
\text { inventário - preservar a cultura material } \\
\text { escolar. }\end{array}$ & $\begin{array}{l}\text { Revista Brasileira de } \\
\text { História da Educação }\end{array}$ & $\underline{\text { Link }}$ \\
\hline 2011 & $\begin{array}{l}\text { Carmen Sylvia } \\
\text { Vidigal Moraes; } \\
\text { Daniel Righi; } \\
\text { Luciana Santos e } \\
\text { Tatiana Calsavara }\end{array}$ & $\begin{array}{c}\text { Inventário de fontes das escolas dirigidas pelo } \\
\text { educador anarquista João Penteado (1912- } \\
\text { 1961): dimensão pedagógica e contribuição } \\
\text { para a história da relação trabalho e educação } \\
\text { no Brasil. }\end{array}$ & $\begin{array}{l}\text { Revista Brasileira de } \\
\text { História da Educação }\end{array}$ & $\underline{\text { Link }}$ \\
\hline 2013 & $\begin{array}{l}\text { Ana Caroline Pereira } \\
\text { da Cruz }\end{array}$ & $\begin{array}{l}\text { Educação pública e arquivos: uma abordagem } \\
\text { sobre a formação de professores das séries } \\
\text { iniciais em Dourados (1970-2000) }\end{array}$ & $\begin{array}{l}\text { Horizontes - Revista } \\
\text { de Educação }\end{array}$ & $\underline{\text { Link }}$ \\
\hline 2018 & $\begin{array}{l}\text { Yohana T. } \\
\text { Hoffmann e David } \\
\text { A. Costa }\end{array}$ & $\begin{array}{l}\text { História da educação matemática: } \\
\text { conservação da cultura escolar }\end{array}$ & $\begin{array}{l}\text { Revista Latino- } \\
\text { americana de } \\
\text { investigación em } \\
\text { matemática educativa }\end{array}$ & $\underline{\text { Link }}$ \\
\hline
\end{tabular}

Fonte: Elaborado pelos autores e pela autora a partir do Portal de periódicos da Capes/MEC, fevereiro, 2021.

Dentre os trabalhos do primeiro conjunto destaca-se 4 trabalhos de pesquisa: "Os arquivos escolares como fonte para a história da educação" (BONATO, 2005). Seu objetivo foi elaborar um diagnóstico da situação em que se encontravam os arquivos escolares no Rio de Janeiro. Utilizando-se de pesquisa bibliográfica para contextualizar os arquivos encontrados. Concluiu-se que tanto a organização quanto a preservação necessitam ser pensadas a partir da função social e crítica de arquivos escolares. Também no trabalho de pesquisa intitulado "Currículos, práticas e cotidiano escolar: a importância dos arquivos escolares para a produção de conhecimento em história da educação" (GATTI JR. e PESSANHA, 2010), o objetivo central foi detalhar a localização e as condições das fontes, bem como a descrição física e de conteúdo de cada arquivo. Autor e autora concluem, na esteira do que delimita a literatura específica sobre o estatuto dos arquivos escolares e seu papel na investigação em História da Educação, que se deve superar 
o enfoque sobre o macrossocial, considerar os processos que envolvem o conceito de cultura escolar e valorizar o papel que desempenham os arquivos escolares na pesquisa históricoeducacional além das macro abordagens.

Outro ponto significativamente salientado nesse primeiro conjunto de trabalhos detém relação com uma discussão importante acerca dos "lugares" dos arquivos escolares na produção de conhecimento histórico-educacional e dos "lugares" dos tipos de fontes para e nos arquivos escolares. Além de refletir acerca do lugar dos arquivos escolares nas instituições educativas, a natureza dos documentos e suas potencialidades de investigação, o "lugar" do arquivo precisa admitir, conforme esses trabalhos, não só a pertinência em termos de pesquisa historiográfica, mas também a pertinência em relação à visibilidade na comunidade. Isso implica em organizar atividades culturais, eventos diversos para recuperar a memória educativa e valorizar as realidades cultural e pedagógica com professores e professoras, estudantes, famílias, etc. visando, principalmente, a constituição de fundos de caráter museológico e arquivístico nas instituições escolares. Essa é, por exemplo, uma das sugestões centrais do trabalho “Arquivos e educação: a construção da memória educativa” (MOGARRO, 2005). Também o artigo intitulado "Arquivos ou museus: qual o lugar dos acervos escolares?” (BARLETTA, 2005), constrói argumentação interessante sobre os "lugares" dos objetos em arquivos escolares. O texto buscou contribuir para uma discussão sobre os "lugares" dos objetos nos arquivos escolares, propondo, a partir de alguns princípios da arquivologia, que não são quaisquer objetos, mas apenas determinados conjuntos de objetos, ligados diretamente às funções primordiais de uma instituição, que devem integrar os arquivos.

Mais 3 trabalhos de pesquisa detalham possibilidades e potencialidades de fontes em arquivos escolares. Extremamente significativo nesses trabalhos é que, além da reflexão sobre suas proposições específicas de pesquisa e o recurso aos arquivos escolares, também descrevem as potencialidades e as possibilidades dessas fontes. O trabalho intitulado "Inventário de fontes das escolas dirigidas pelo educador anarquista João Penteado (1912-1961): dimensão pedagógica e contribuição para a história da relação trabalho e educação no Brasil”' (MORAES et al., 2011), além de refletir sobre seu objeto específico, buscou ressaltar a pertinência das fontes utilizadas em outras questões substantivas: apreender a dinâmica de permanências e mudanças no campo políticopedagógico, a ação docente, a escolarização dos conhecimentos e o lugar atribuído às mulheres na sociedade e no ensino. Outros trabalhos também fundamentam alusões semelhantes: "Educação pública e arquivos: uma abordagem sobre a formação de professores de séries iniciais em Dourados (1970-2000)" (HOFFMANN e COSTA, 2018) e "História da educação matemática: conservação 
da cultura escolar" (CRUZ, 2013). Esse último, ao tratar da primeira instituição pública de formação de professores das séries iniciais em Dourados, chama a atenção para os documentos encontrados no arquivo desta escola, que apontam para outras possibilidades de pesquisa além das que são demonstradas diretamente em seu trabalho. Já o de autoria de Hoffmann e Costa (2018) ressalta o trabalho coletivo do Grupo de Pesquisa de História da Educação Matemática no Brasil (GHEMAT), apontando suas recentes mobilizações e a importância de realizar pesquisas voltadas para o interior das instituições escolares, além de descrever as potencialidades dessas fontes para problematizar a educação matemática, visando a realização de novas investigações.

O segundo conjunto inclui 3 trabalhos de pesquisa que se detiveram a construir "base de dados", "sistematização de fontes" e "inventário de documentos" apontando para o elemento organizativo das fontes provenientes de arquivos escolares. São, de fato, fundamentais para os objetivos que estamos traçando em nosso percurso, pois alertam para a dimensão organizativa das fontes. O trabalho desenvolvido por Valente (2005), salienta que armazenar dados em CD-Rom ou em plataformas digitais/virtuais poderia facilitar o acesso de quem deseja pesquisar nesses arquivos. Mais do que isso, o autor critica a frequência com que as pesquisas realizadas em arquivos escolares não deixam disponibilizadas e sistematizadas as fontes trabalhadas para outros investigadores e investigadoras, obrigando a repisar percursos que já foram trilhados na organização desses materiais. Já as pesquisas “Arquivos escolares: a experiência do GEM/MT” (SIQUEIRA, 2005) e "Descrever os documentos - construir o inventário - preservar a cultura material escolar" (MENEZES, 2011), ao localizar e sistematizar documentos concernentes à educação escolar no estado de Mato Grosso e apresentar a construção de um inventário de documentos do arquivo histórico da "antiga" Escola Normal de Campinas, respectivamente, mostraram-se fortemente preocupados em construir base de dados e inventários que servissem a novas iniciativas de investigação nos mais diferentes temas.

O terceiro conjunto corresponde a um trabalho que consideramos mais ousado. Além de expor as experiências que resultaram do tratamento dos documentos de escolas públicas de São Paulo, o trabalho "O lugar do arquivo permanente dentro de um centro de memória escolar" (ZAIA, 2005), sugere a criação de um centro de memória escolar capaz de contemplar não só documentos administrativos e legais, mas também peças, quadros, mapas, cadernos de alunos, além de outros tipos documentais. Suas proposições baseiam-se na interdisciplinaridade entre arquivologia, museologia e biblioteconomia repassadas em constante diálogo com a prática de pesquisa em História da Educação. 
Mesmo em trabalhos que não se detiveram especificamente à organização, descrição e sistematização de fontes provenientes de arquivos escolares, pesquisadoras e pesquisadores têm se preocupado em apresentar panoramas gerais do conjunto de fontes trabalhadas durante seus percursos investigativos, ainda que isso não se repita na maioria dos trabalhos. Isso repercute na valorização dos acervos documentais em escolas de diferentes regiões do país. Valorizar a memória educativa e a História da Educação passa pelo reconhecimento da necessidade de ações múltiplas, dos governos, das escolas e das comunidades, que destaquem a importância dos arquivos escolares em sua dimensão cultural, social, crítica e política.

\section{Conclusão}

Nesse texto apresentamos o mapeamento preliminar de trabalhos produzidos no Brasil, no campo da História da Educação, que tiveram os arquivos escolares como objeto central de reflexão. Buscamos compreender, a partir do levantamento realizado, o que dizem, afinal, esses trabalhos sobre organizar, sistematizar, preservar e inventariar fontes de arquivos escolares para a História da Educação. Na primeira parte do texto, como dissemos, trabalhamos em favor de relatar as estratégias e os pressupostos que orientaram a realização do levantamento no Portal de Periódicos Capes/MEC, buscando ressaltar que a escolha dos termos-chave (descritores) provém das leituras coletivas realizadas em nosso Grupo de Pesquisa, além de se configurarem como estratégicas para cercar o objeto de investigação. Na segunda parte, identificamos os objetivos e as principais considerações dos trabalhos de pesquisa que se detiveram aos arquivos escolares como objetos centrais de suas reflexões a fim de traçar os contornos das possibilidades de nossa incursão pelos arquivos escolares da região dos vales, especialmente do município de Santa Cruz do Sul.

No decorrer da realização do levantamento, foi possível perceber que os trabalhos de pesquisa que se detiveram ao estudo de arquivos escolares denotam diferentes percursos e experiências, o que nos sugere possibilidades úteis para novas pesquisas. Os trabalhos chamam a atenção para a necessidade de se preservar esses arquivos valorizando a memória educativa através de múltiplas ações que devem envolver diferentes sujeitos nas escolas e na comunidade. A descrição, sistematização, organização de fontes é tarefa central de toda e qualquer investigação que se utiliza de acervos provenientes de arquivos escolares e não somente daquelas que se dirigem mais diretamente à constituição de inventários. É imprescindível que pesquisadores e pesquisadoras assumam isso como premissa em seus trabalhos, não só para contribuir com o campo de produção histórico-educacional, auxiliando pesquisas vindouras, mas, cada vez mais, valorizar e chamar a atenção para a existência e a situação dos arquivos escolares no país. 
SOUZA, Joice Nunes de; ALMEIDA, Diego Orgel Dal Bosco; SILVEIRA, Éder da Silva. Arquivos escolares e História da Educação: o que dizem os artigos do Portal de Periódicos da Capes/MEC (2002-2019)

\section{Agradecimentos}

O presente artigo foi realizado com apoio da Coordenação de Aperfeiçoamento de Pessoal de Nível Superior - Brasil (CAPES) e do Conselho Nacional de Desenvolvimento Científico e Tecnológico - Brasil (CNPq).

\section{Referências}

ABREU JR, Laerthe de Moraes; GUIMARÃES, Paula David. A Cultura Material Escolar como Fonte de Pesquisa das Práticas Escolares em São João del-Rei, MG (1938-1944). Educaşão: Teoria e Prática, v. 21, n. 36, p. 181-200, 2011. Disponível em:

<https://www.periodicos.rc.biblioteca.unesp.br/index.php/educacao/article/view/3594>.

Acesso em: 29 mar. 2021.

BARLETTA, Jacy Machado. Arquivos ou museus: qual o lugar dos acervos escolares?. Revista Brasileira de História da Educação, n 10 jul./dez. 2005. Disponível em:

$<$ https://periodicos.uem.br/ojs/index.php/rbhe/article/view/38648>. Acesso em: 29 mar. 2021.

BASTOS, Maria Helena Câmara; BILHÃO, Isabel; SILVEIRA, Éder da Silva. Quando a recordação é referência: reflexões e experiências de uma professora/pesquisadora no campo da história da educação. Reflexão e Ação, Santa Cruz do Sul, v. 27, n. 3, p. 247-259, out. 2019. Disponível em: <http://online.unisc.br/seer/index.php/reflex/article/view/14098>. Acesso em: 22 março de 2021.

BELLOTTO, Heloísa Liberalli. Patrimônio documental e ação educativa nos arquivos. Ciências e Letras (Porto Alegre), Porto Alegre, n.27, p. 151-166, jan/jun. 2000.

BONATO, Nailda Marinho da Costa. Os arquivos escolares como fonte para a história da educação. Revista Brasileira de História da Educaşão, v. 5 n. 2 [10], p. 193-220. 2005. Disponível em: $<$ https://periodicos.uem.br/ojs/index.php/rbhe/article/view/38652>. Acesso em: 29 mar. 2021.

CAVALCANTE, Aline Nascimento; FURTADO, Alessandra Cristina. Organização e digitalização de documentos sobre a formação e profissionalização de professores das escolas rurais de Dourados e região (1988-1996). Interfaces da Educ., Paranaíba, v.4, n.12, p. 20-33, 2014. Disponível em: < https://periodicosonline.uems.br/index.php/interfaces/article/view/508>. Acesso em: 29 mar. 2021.

CIGALES, Marcelo; ARRIADA, Eduardo. A sociologia educacional católica no sul do Brasil (1940-1970): um estudo a partir do corpo docente. Acta Scientiarum. Education, v. 41, e35252, 2019. Disponível em: <https://periodicos.uem.br/ojs/index.php/ActaSciEduc/article/view/35252>. Acesso em: 29 mar. 2021. 
SOUZA, Joice Nunes de; ALMEIDA, Diego Orgel Dal Bosco; SILVEIRA, Éder da Silva. Arquivos escolares e História da Educação: o que dizem os artigos do Portal de Periódicos da Capes/MEC

CRUZ, Ane Caroline Pereira. Educação pública e arquivos: uma abordagem sobre a formação de professores das séries iniciais em Dourados (1970-2000). Horizontes-Revista de Educação, v. 1, n. 1, p. 155-156, 2013. Disponível em:

<https://ojs.ufgd.edu.br/index.php/horizontes/article/view/2490>. Acesso em: 29 mar. 2021.

FERREIRA, Norma Sandra de Almeida. As pesquisas denominadas "estado da arte". Educação \& Sociedade, São Paulo, ano 23, n. 79, p. 257-272, ago. 2002. Disponível em:

<https://www.scielo.br/scielo.php?pid=s010173302002000300013\&script=sci_abstract\&tlng=p t>. Acesso em: 11 de mar. 2021.

GATTI JÚNIOR, Décio; PESSANHA, Eurize Caldas. Currículos, práticas e cotidiano escolar: a importância dos arquivos escolares para a produção de conhecimento em história da educação.

História da Educação, ASPHE/FaE/UFPel, Pelotas, v. 14, n. 31 p. 155-191, Maio/Ago 2010.

Disponível em: <https://seer.ufrgs.br/asphe/article/view/28854>. Acesso em: 29 mar. 2021.

HIDALGO, André Vinícius. Educação Física escolar no Curso de Formação em Nível Médio para professores Guarani e Kaiowá: memória da turma 2001. Horizontes-Revista de Educação, v. 3, n. 4. 2014. Disponível em: <https://ojs.ufgd.edu.br/index.php/horizontes/article/view/5193>. Acesso em: 29 mar. 2021.

HOFFMANN, Yohana T.; COSTA, David A. História da educação matemática: conservação da cultura escolar. Revista latinoamericana de investigación en matemática educativa, v. 21, n. 1, p. 11-28, 2018. Disponível em: <http://www.scielo.org.mx/scielo.php?script=sci_arttext\&pid=S166524362018000100011>. Acesso em: 29 mar. 2021.

JULIA, Dominique. A cultura escolar como objeto histórico. Revista brasileira de história da educação, v. 1, n. 1 [1], p. 9-43, 2001.

MOGARRO, Maria. João. Arquivo e educação: a construção da memória educativa. Revista Brasileira de História da Educação, n.10, p. 75-99, jul./dez. 2005. Disponível em:

<https://periodicos.uem.br/ojs/index.php/rbhe/article/view/38647>. Acesso em: 29 mar. 2021.

MENEZES, Maria Cristina. Descrever os documentos-construir o inventário-preservar a cultura material escolar. Revista Brasileira de História de Educação, v. 11, n. 1 (25), p. 93-116, jan./abr. 2011. Disponível em: <https://periodicos.uem.br/ojs/index.php/rbhe/article/view/38508>. Acesso em: 29 mar. 2021.

MORAES, Carmen Sylvia Vidigal et al. Inventário de fontes das escolas dirigidas pelo educador anarquista João Penteado (1912-1961): dimensão pedagógica e contribuição para a história da relação trabalho e educação no Brasil. Revista Brasileira de História de Educação, v. 11, n. 1 (25), p. 117-142, jan./abr. 2011. Disponível em:

<https://periodicos.uem.br/ojs/index.php/rbhe/article/view/38509>. Acesso em: 29 mar. 2021.

MOROSINI, Marília Costa; FERNANDES, Cleoni Maria Barboza. Estado do Conhecimento: conceitos, finalidades e interlocuções. Educaşão Por Escrito, Porto Alegre, v. 5, n. 2, p. 154-164, jul.-dez. 2014. Disponível em:

$<$ https://revistaseletronicas.pucrs.br/ojs/index.php/porescrito/article/view/18875>. Acesso em: 11 de mar. 2021. 
NOSELLA, Paulo; BUFFA, Ester. As pesquisas sobre instituições escolares: balanço crítico. II Colóquio sobre Pesquisa de Instituições Escolares. Anais. UNICAMP/ Campinas/UNINOVE, São Carlos. 2006.

NÓVOA, António. Apresentação: Por que a História da Educação? In: STEPHANOU, Maria; BASTOS, Maria Helena Câmara. Histórias e Memórias da Educação no Brasil, Vol. III - Século XX. 4.ed. Petrópolis/RJ: Vozes, 2011, p. 9-13.

SIQUEIRA, Elizabeth Madureira. Reconstituindo arquivos escolares. A experiência do GEM/MT. Revista Brasileira de História da Educação, nº 10 jul./dez. 2005. Disponível em: $<$ https://periodicos.uem.br/ojs/index.php/rbhe/article/view/38649>. Acesso em: 29 mar. 2021.

SOUZA, Joice Nunes de; ALMEIDA, Diego Orgel Dal Bosco; SILVEIRA, Éder da Silva. Sondando um arquivo escolar: reflexões sobre memória, história e fontes para a História da Educação em Santa Cruz do Sul/Brasil. Textura (Ulbra), vol. 22, n. 52, Out./Dez, 2020, p. 417 438. Disponível em:

<http://www.periodicos.ulbra.br/index.php/txra/article/view/5662/3908>. Acesso em: 11 de mar. 2021.

STEPHANOU, Maria; BASTOS. Maria Helena Camara, História, Memória e História da Educação. In: STEPHANOU, Maria; BASTOS. Maria Helena Camara (org.). Histórias e memórias da educação no Brasil, vol. III: século XX. 4. ed. Petrópolis, Rio de Janeiro: Vozes, 2011. p. 416-435.

VALENTE, Wagner Rodrigues. Arquivos escolares virtuais considerações sobre uma prática de pesquisa. Revista Brasileira de História da Educação, nº 10 jul./dez. 2005. Disponível em:

<https://periodicos.uem.br/ojs/index.php/rbhe/article/view/38651>. Acesso em: 29 mar. 2021.

VIÑAO FRAGO, António. Relatos e relações autobiográficas de professores e mestres. In: MENEZES, Maria Cristina. (Org.). Educação, memória, história: possibilidades, leituras.

Campinas/SP: Mercado das Letras, 2004, p. 333-374.

WERLE, Flávia Obino Corrêa. Documentos escolares: impactos das novas tecnologia. Revista História da Educação, v. 6, n. 11, jan./jun. 2002. Disponível em:

<https://seer.ufrgs.br/index.php/asphe/article/view/30600>. Acesso em: 29 mar. 2021.

WERLE, Flávia Obino Corrêa. O rádio e a educação rural no Rio Grande do Sul (1940-1960). Revista História da Educação, v. 15 n. 35 Set./dez. p. 127-154. 2011. Disponível em: <https://seer.ufrgs.br/index.php/asphe/article/view/22198>. Acesso em: 29 mar. 2021.

ZAIA, Iomar Barbosa. O lugar do arquivo permanente dentro de um centro de memória escolar. Revista Brasileira de História da Educação, n 10 jul./dez. 2005. Disponível em: <https://periodicos.uem.br/ojs/index.php/rbhe/article/view/38650>. Acesso em: 29 mar. 2021. 